\title{
Multiple Optical Features In Binary-Transition-Metal Borate Glasses
}

\section{Moukhtar A. Hassan}

Al-Azhar University Faculty of Science

\section{A. Ashoush}

Al-Azhar University Faculty of Science

\section{F. M. Ebrahim}

Al-Azhar University Faculty of Science

\section{M. EL Hady}

Al-Azhar University Faculty of Science

\section{F. Ahmad}

Al-Azhar University Faculty of Science for Girls in Cairo

\section{Zakaria M Abd El-Fattah ( $\square$ zakaria.eldegwy@gmail.com )}

Al-Azhar University Faculty of Science https://orcid.org/0000-0003-2385-7704

\section{Research Article}

Keywords: Hybrid transition metal glasses, Chromium ions, Copper ions, Ligand field, ESR, FTIR

Posted Date: June 15th, 2021

DOI: https://doi.org/10.21203/rs.3.rs-583999/v1

License: (c) (i) This work is licensed under a Creative Commons Attribution 4.0 International License. Read Full License

Version of Record: A version of this preprint was published at Optical and Quantum Electronics on August 6th, 2021. See the published version at https://doi.org/10.1007/s11082-021-03095-4. 


\section{Abstract}

Glasses doped with transition metal (TM) ions exhibit rich optical transitions spanning the entire ultraviolet, visible, and infrared spectral regimes. Here we utilize the melt-quenching techniques to synthesis binary-TM-doped borate glasses of composition $x$ CuO- $(75-x) \mathrm{B}_{2} \mathrm{O}_{3}-24.7 \mathrm{Li}_{2} \mathrm{O}-0.3 \mathrm{Cr}_{2} \mathrm{O}_{3}$, with $x=0$, $0.2,1.0$ and $2.0 \mathrm{~mol} \%$. We identify several optical transitions from $\mathrm{Cr}^{3+}, \mathrm{Cr}^{6+}$, and $\mathrm{Cu}^{2+}$ ions, the latter manifests at longer wavelengths and gains higher intensity with $\mathrm{Cu}$ additives. Despite $\mathrm{Cr}$ concentration being fixed, the $\mathrm{Cr}^{6+}$ peaks are quenched and $\mathrm{Cr}^{3+}$ signals are barely attenuated. This behavior rules out possible phase separation and suggests non-trivial interplay between the two TM ions and ligand, as supported by probing their oxidation states from electron spin resonance. The crystal field and Racah parameters followed an opposite behavior, while the optical band gap is reduced upon doping. These changes are correlated with structural modifications introduced by $\mathrm{Cu}$ additives, where we anticipate homogenous and preferential proximity of $\mathrm{Cu}-\mathrm{Cr}$ ions within the network.

\section{Introduction}

Transition metal (TM) ions offer unique structural probes for the local environments within amorphous glasses, due to their distinguished wide-radial-distribution of the outer $d$-shell electronic configurations, which renders TM ions highly sensitive to minimal changes in compositions and/or structures of the surrounding ligands [1-5]. The interaction between TM ions and the non-spherically symmetric ligands induces energy splitting of the otherwise degenerate $d$-electrons, which show up as spectral peaks in conventional optical spectroscopies. Many such optical transitions often take place in the visible spectral region, thereby imparting glasses with distinct colors which are tunable through the TM ion type, concentration, and the overall composition of the glass host [6]. Chromium ( $\mathrm{Cr}$ ), among other TM ions, is enormously important for the development of tunable solid state lasers, optical fibers, and as active component in luminescence materials, as it can exist in different oxidation states, the most abundant of which are $\mathrm{Cr}^{3+}$ and $\mathrm{Cr}^{6+}[7-10]$. Moreover, $\mathrm{Cr}$ ions also act as glass modifiers, so that these distinctive oxidation states within the structural units constituting the glass could be regulated by suitable selection of the glass modifiers/formers, by the size and field strength of the ions, and eventually by the mobility of the modifier cations [10-14]. Optical transitions solely stemming from $\mathrm{Cr}$ ions can span the ultraviolet $\left(\mathrm{Cr}^{6+}\right)$ and visible $\left(\mathrm{Cr}^{3+}\right)$ spectral regimes, the former could be readily identified for diluted $\mathrm{Cr}$ ion concentrations [14].

Likewise, TM copper ( $\mathrm{Cu}$ ) ions with $3 d^{9}$ electronic configuration, exhibits interesting electrical and optical properties which make them appealing candidates for superionic conductors and solid state lasers [15]. They can also be loaded with higher concentrations without disrupting the amorphous nature of the host glass $[3,16,17]$. Analogous to the split- $d$-bands in $C r$, the ground state of free $\mathrm{Cu}$ ions $\left({ }^{2} \mathrm{D}\right)$ splits in an octahedral crystal field into ${ }^{2} \mathrm{E}_{\mathrm{g}}$ and ${ }^{2} \mathrm{~T}_{2 \mathrm{~g}}$. Such a splitting manifests in the optical spectra as a broad resonance in the red side of the electromagnetic spectrum, near the infrared [3, 16-19]. Additional splitting of ${ }^{2} \mathrm{E}_{g}$ and ${ }^{2} \mathrm{~T}_{2 g}$ states, in a tetragonally-distorted octahedral coordination with six oxygen 
ligands, into $\left({ }^{2} B_{1}\right.$ and $\left.{ }^{2} A_{1}\right)$ and $\left({ }^{2} E\right.$ and $\left.{ }^{2} B_{2}\right)$ takes place due to Jahn-Teller effect $[3,18-21]$, which could lead to more optical transitions in the ultraviolet regime. Information regarding levels splitting just discussed for $\mathrm{Cr}$ and $\mathrm{Cu}$ TM ions could readily be inferred from optical and electron spin resonance (ESR) spectroscopies, where the latter identifies the oxidation states of TM ions exclusively with unpaired electrons.

Among different TM glass hosts, borate glasses are appealing given its various wonderful properties, such as low melting point, moisture resistance, good thermal stability, and fantastic optical properties [22, 23]. They consist of a complex three-dimensional network of boron and oxygen, which in the present of low-level alkali oxide such as lithium oxide, develop the most stable $\mathrm{BO}_{4}$ derived from the conversion of triangular borate structural units $\left(\mathrm{BO}_{3}\right)$. Such alkali-oxide borate glasses can accommodate various types and concentrations of TM ions.

Here, we utilize an alkali-borate glass host to explore the optical properties and oxidation states imparted by a combination of binary TM ions, namely $\mathrm{Cr}$ and $\mathrm{Cu}$. The two TM ions coherently mix into a rather homogenous glass, where the measured optical spectra clearly exclude possible phase separation. Specifically, we find a complete quenching of $\mathrm{Cr}^{6+}$ features and attenuated signals from $\mathrm{Cr}^{3+}$, while $\mathrm{Cu}^{2+}$ resonances become dominant at higher Cu-doping levels.

\section{Experimental Techniques}

Hybrid TM-doped alkali-borate glass system with composition $x$ CuO- $(75-x) \mathrm{B}_{2} \mathrm{O}_{3}-24.7 \mathrm{Li}_{2} \mathrm{O}-0.3 \mathrm{Cr}_{2} \mathrm{O}_{3}(x=0$, $0.2,1.0$, and $2.0 \mathrm{~mol} \%$ ) was prepared by melt quenching technique. The respective amounts of the powder oxides were melted in an electrical furnace, under ordinary atmospheric conditions, at $1100^{\circ} \mathrm{C}$ for one hour until a bubble-free liquid was formed. The molten were quenched rapidly to room temperature between two polished copper plates. Green-blue colored glasses with high optical quality and transparency were obtained. Optical absorption spectra of the glass samples were recorded using JenWay-6405-type UV-VIS spectrophotometer in the 190-1100 nm spectral range. Electron spin resonance (ESR) data were collected using EMX Bruker type spectrometer, operating at the X-band frequency with $100 \mathrm{kHz}$ field modulation and $10 \mathrm{~mW}$ microwave power. The magnetic field was varied between 100 to $4000 \mathrm{G}$. For a reasonable quantitative spin analysis, the weight of the powder is kept fixed for all samples. Infrared absorption spectra were recorded in the range 400-1600 cm-1 using FTIR Nicolet 6700 spectrometer, on powdered samples pressed into disks after mixing with high purity $\mathrm{KBr}$.

\section{Results And Discussion}

\subsection{Optical Absorption Spectroscopy:}

The optical absorption spectra of two reference samples are presented in Fig. 1(a). These are Cu-free sample containing $0.3 \mathrm{~mol} \% \mathrm{Cr}$ (red), and Cr-free sample with $1.0 \mathrm{~mol} \% \mathrm{Cu}$ (black), so that we easily identify optical contributions from individual TM ions. The Cu-free sample $(x=0.0)$ exhibits multiple 
optical transitions in the ultraviolet and visible spectral regimes which are indicated by arrows and are, respectively, assigned to $\mathrm{Cr}^{6+}$ and $\mathrm{Cr}^{3+}[7,10,24]$. The sample with $\mathrm{Cu}$ concentration of $(x=1.0)$ but containing no $\mathrm{Cr}$ ions, is characterized by a broad absorption spanning the wide spectral region $>500 \mathrm{~nm}$, and belongs to optical transition from $\mathrm{Cu}^{2+}$ ions $[3,17]$. These two reference samples are characterized by distinct colors (see insets in a) derived from $\mathrm{Cu}^{2+}$ (bluish) and exclusively $\mathrm{Cr}^{3+}$ transition at $\sim 620 \mathrm{~nm}$ (greenish). The mathematical summation of the two spectra in (a) yields the yellow spectrum in Fig. 1(b), which obviously contains contributions from $\mathrm{Cr}^{6+}, \mathrm{Cr}^{3+}$, and $\mathrm{Cu}^{2+}$ ions. This is compared to a prepared sample (green spectrum in (b)) consisting of the respective $\mathrm{Cu}$ and $\mathrm{Cr}$ amounts, i.e., $1.0 \mathrm{~mol} \% \mathrm{Cu}$ and 0.3 mol\% Cr. We note that, for such hybrid TM sample, $\mathrm{Cr}^{3+}$ transitions are only slightly attenuated while $\mathrm{Cr}^{6+}$ are entirely suppressed, despite the $\mathrm{Cr}$ amount is fixed for both samples in (a). This sharp contrast between the two spectra in (b) confirms the homogeneity of the two TM ions within the samples, so that no phase separation between areas with single type TM ions is taking place. Given that $\mathrm{Cr}^{3+}$ transition, which is responsible for the color, is only minimally affected, the final glass color of this TM hybrid system (see insets in b) is the simple summation of the two colors in (b). In order to follow these spectral changes in such homogenous and binary TM-doped systems, we present in Fig. 2 the optical absorption spectra for a series of Cu-doped samples $(x=0,0.2,1.0,2.0 \mathrm{~mol} \%)$ with fixed $\mathrm{Cr}$ concentration ( $0.3 \mathrm{~mol}$ $\%)$.

The spectra exhibit clear suppression of $\mathrm{Cr}^{6+}$ transitions at ( 339 and $\sim 370 \mathrm{~nm}$ ) and slight attenuation of the spin-allowed ${ }^{4} \mathrm{~A}_{2}(\mathrm{~F}) \rightarrow{ }^{4} \mathrm{~T}_{1 \mathrm{~g}} \mathrm{Cr}^{3+}$ transition around $418 \mathrm{~nm}$. In fact, the two $\mathrm{Cr}^{6+}$ transitions, which originate from ${ }^{4} \mathrm{~A}_{2 g} g \rightarrow{ }^{4} \mathrm{~T}_{1}(\mathrm{P})$ and ${ }^{4} \mathrm{~A}_{2 g} \rightarrow{ }^{4} \mathrm{~A}_{1 \mathrm{~g}}$, is only barely recognized for the least Cu-doped sample $(x=0.2 \mathrm{~mol} \%)$. On the other hand, the broad spectral transition in the region $(530-1100 \mathrm{~nm})$, which belongs to $\mathrm{Cu}^{2+2} \mathrm{E}_{\mathrm{g}} \rightarrow{ }^{2} \mathrm{~T}_{2 \mathrm{~g}}$ transition [3, 4, 15-19], gains noticeably larger intensity with $\mathrm{Cu}$ additives. Indeed, the center of gravity of this broad transition, which is located near $790 \mathrm{~nm}$ (Fig. 1(a)) for the Crfree sample, progressively shifts towards shorter wavelengths, thereby mixing with the band position of the nearby spin-allowed ${ }^{4} \mathrm{~A}_{2 \mathrm{~g}} \rightarrow{ }^{4} \mathrm{~T}_{2 \mathrm{~g}} \mathrm{Cr}^{3+}$ transition at $\sim 623 \mathrm{~nm}$. Notice that the intensity of this $\mathrm{Cr}^{3+}$ signal, which is responsible of the greenish color of the samples [10, 29-34], is likely barley affected, since the overall hybrid glass samples exhibit an intermediate color between the greenish-bluish extremes (see insets in Fig. 1).

The tunable $\mathrm{Cr}$ optical transitions, here reported for fixed $\mathrm{Cr}$ concentration, clearly demonstrates that $\mathrm{Cu}$ additives modify the ligand environment around $\mathrm{Cr}$ ions within the glass host. Such information can be coined within a set of ligand field parameters, namely the crystal field (10Dq) and Racah parameters (B \& C). Their determination for a given TM ion demand knowledge of the position of all its absorption peaks, which could be precisely extracted via a deconvolution process, as exemplified at the inset of Fig. 2 . The magnitude of $10 \mathrm{Dq}$ is then determined from the simple one-to-one relation [10, 35-38],

$10 \mathrm{Dq}=\mathrm{u}_{1},(1)$

while the Racah parameters (B \& $C$ ) are given by the following equations: 
$C=\left(U_{3}-4 B-v_{1}\right) / 3,(3)$

where $v_{1}, v_{2}$, and $v_{3}$ refer to the peak position of the high/low energy $\mathrm{Cr}^{3+}$ transitions and the average of $\mathrm{Cr}^{6+}$ peaks, respectively. The estimated values of $10 \mathrm{Dq}$ and both B \& C parameters are plotted in Fig. 3(ab) as a function of the Cu content. While 10Dq parameter (a) clearly decreases with Cu additives, both Racah parameters (b) follow the opposite behavior. These results suggest strong electron localization at $\mathrm{Cr}^{3+}$ ions and, therefore, the $d$ shell inter-electronic repulsion (encoded in $\mathrm{B} \& \mathrm{C}$ ) becomes comparatively more intense, leading to chemical bonds of more ionic character between $\mathrm{Cr}^{3+}$ ions and ligands $[4,5,39$, 40].

With regard to the crystal field of $\mathrm{Cu}$ ions, it is well known that $\mathrm{Cu}^{2+}\left(3 d^{9}\right)$ in octahedral crystal field loses its degeneracy and splits into ${ }^{2} \mathrm{E}_{g}$ and ${ }^{2} \mathrm{~T}_{2 \mathrm{~g}}$ with ${ }^{2} \mathrm{E}_{\mathrm{g}}$ being the lower level. Generally speaking, $\mathrm{Cu}^{2+}$ ions are often found in octahedral sites, and the ${ }^{2} \mathrm{E}_{\mathrm{g}}$ state splits due to Jahn-Teller effect. Therefore, the here observed red shift of the broad $\mathrm{Cu}^{2+}$ optical transition $(\sim 800 \mathrm{~nm})$ indicates that $\mathrm{Cu}$ ions occupy tetragonally-distorted octahedral symmetry as discussed later from ESR results [3,16-19]. The consequent of such a distortion on the shielding of the atomic charges affects the energy involved in the ${ }^{2} \mathrm{E}_{\mathrm{g}} \rightarrow{ }^{2} \mathrm{~T}_{2 \mathrm{~g}}$ transition, which become lower as the inner shell electron density is increased.

Finally, we shed the light into a physical quantity which encompasses valuable information about the momentum-integrated band structure of the whole glass system, namely the optical band gap $\left(E_{\mathrm{g}}\right)$. This is often determined from absorption spectra by utilizing Tauc's routine applied to the linear part of the absorption edge, as depicted in Fig. 3(c). The estimated band gap presented in Fig. 3(d) as a function of Cu content, was found to decrease by $\sim 0.32 \mathrm{eV}$ at the highest Cu-doing level ( $2.0 \mathrm{~mol} \%)$. This behavior of the band gap can be traced back to additional defect states introduced by $\mathrm{CuO}$ into the glass matrix, but also relates to the increased concentration of $\mathrm{BO}_{4}$ structural units and the creation of bridging oxygen (BO), as we discuss later through the FITR section $[2,10,41]$.

\subsection{Electron Spin Resonance Spectroscopy:}

The ESR spectra of all samples $(x=0,0.2,1.0$, and $2.0 \mathrm{~mol} \%)$ are shown in Fig. 4 . We initiate the analysis and discussion here by first exploring the spectra of two reference samples, namely Cr-free $(x=1.0, \mathrm{Cr}=0)$ and Cu-free $(x=0, \mathrm{Cr}=0.3)$, depicted at the upper inset. We utilized this strategy to distinguish features originating due to $\mathrm{Cr}$ ions from those resulting from $\mathrm{Cu}$ ions. It is clear that there are three signals in the Cu-free sample $(x=0)$, two of which are located at the low field side with effective $g$ values 4.82 and 4.08 , and are often attributed to the presence of $\mathrm{Cr}^{3+}[4,10-14,27]$. The absorption at $g=2.25$ is due to exchange coupled pairs or large $\mathrm{Cr}^{3+}$ clusters, while the resonance located at high field with an effective $g$ value of 1.93 is mainly due to $\mathrm{Cr}^{6+}[10,28]$. For the Cr-free and $(x=1)$ sample, strong signals show up in the range 2800-3600 Gauss, with a well-defined resonance at $g=2.05$ which obviously belong to $\mathrm{Cu}^{2+}$ 
$\left(3 d^{9}\right)$ ions in axially distorted octahedral symmetric sites $[3,17,42-44]$. Additional weak signal from $\mathrm{Cu}^{2+}$ is present at $\mathrm{g}=4.08$, perfectly coinciding with one $\mathrm{Cr}^{3+}$ resonance. The incorporation of $\mathrm{Cu}$ ions onto the Cr-doped borate glasses has pronounced influence on all observed signals as evident from Fig. 4 . The intensity of the two signals with effective $g$ values 4.82 and 4.08 were attenuated by rising $\mathrm{Cu}$ ions (see lower inset), while the $\mathrm{Cr}^{6+}$ signal with $g$ value 1.93 was entirely vanished, in perfect agreement with the Uv-Vis results. The intensities of the signals in the field range 2800-3600 Gauss become noticeably stronger with increasing the $\mathrm{Cu}$ concentration, and exhibit hyperfine interaction (indicated by the four dashed lines) clearly distinguished for the $x=2.0$ sample. Earlier literature [42 -34$]$ reported that $\mathrm{Cu}$ ions reside heavily in tetragonally-distorted octahedral field. Based on Jahn-Teller theorem, the distortion of octahedral symmetry will remove the degeneracies of the ground terms of $\mathrm{Cu}$ ions. The distortion is probably elongated or compressed, which in turn will determine the relative positions of $g_{\|}$and $g_{\perp}$. Here $g_{\|} \approx 2.4$ and $g_{\perp}=2.03$, i.e., $g_{\|} \otimes g_{\perp}$, so that it is reasonable to claim that $\mathrm{Cu}$ ions reside in elongated octahedral distortion $[42,43]$.

\subsection{Infrared Spectroscopy:}

The previously discussed modifications, particularly, in Cr optical and ESR spectra- despite its concentration being fixed- reflects structural rearrangement of ligands surrounding chromium ions, introduced upon $\mathrm{Cu}$ additives. Relevant structural information could be inferred from the FTIR spectra, presented in Fig. 5, for all prepared samples. The spectra mainly consist of three dominant absorption bands often present in alkali-borate glasses [37]. The high wavenumber band $\left(1600-1165 \mathrm{~cm}^{-1}\right)$ is frequently assigned to asymmetric stretching vibration mode of $\mathrm{B}-\mathrm{O}$ within the triangular $\left(\mathrm{BO}_{3}\right)$ structural unit [45]. The nearby band spanning the range $\left(1165-760 \mathrm{~cm}^{-1}\right)$ most likely originates from $\mathrm{B}-0$ stretching vibration within the more stable tetrahedral $\left(\mathrm{BO}_{4}\right)$ structural groups [46]. The last main band in the range $\left(760-590 \mathrm{~cm}^{-1}\right)$ is often ascribed to $\mathrm{B}-\mathrm{O}-\mathrm{B}$ bending vibration of $\mathrm{BO}_{3}$ groups [47]. Additional weak band at the low wavenumber side $\left(<500 \mathrm{~cm}^{-1}\right)$ is discernable, which is predicted to correlate with vibrations from $\mathrm{Cr}^{6+}$ in structural units [10]. It was also equally assigned to ionic vibration from $\mathrm{Li}$ ions, $B-0-B$ bending vibrations, and to borate ring deformations $[43,48,49]$.

The two absorption shoulders identified at 1250 and $900 \mathrm{~cm}^{-1}$ are assigned to asymmetric stretching vibrations of $\mathrm{NBO}$ of $\mathrm{B}-\mathrm{O}-\mathrm{B}$ in tetrahedral and triangular structural units, respectively. The estimated number of $\mathrm{NBO}$ and the $\mathrm{BO}_{4}$ fractions (i.e., the $\mathrm{N}_{4}$ ratio) were found to barley increase (by $2 \%$ ) for the highest Cu-doped sample, indication insignificant structural changes of the main borate structural group. However, the low wavenumber band, which contains partial contribution from $\mathrm{Cr}^{6+}$, is lowered by $~ 5 \%$.

In order to correlate these minimal structural changes with the noticeable variations in optical and ESR spectra, particularly the complete quenching of $\mathrm{Cr}^{6+}$, we discuss possible TM environments through the structural model presented in Fig. 6. In Fig. 6 we envision a structural model containing isolated, adjacent, and shared $\mathrm{Cr}$ and $\mathrm{Cu}$ octahedrons within alkali-borate network. The model is obtained using Avogadro's software $[50,51]$ utilizing the UFF algorithm for forces minimization. The glass network consists mainly 
of $\mathrm{BO}_{3}$ structural units (red shaded planner triangle), in addition to $\mathrm{NBO}$ (blue atoms) and $\mathrm{BO}_{4}$ structural groups (red shaded tetrahedron) produced by Li additives.

For diluted concentrations of TM ions, such as those considered here ( $\leq 2.3 \mathrm{~mol} \%)$, the borate structural units are practically unaffected upon doping, so that the ratios $\mathrm{NBO}, \mathrm{BO}_{3}$, and $\mathrm{BO}_{4}$ are mainly determined by the fixed alkaline $(\mathrm{Li})$ percentage, as concluded from FTIR results. Although this valid for the three $\mathrm{Cr}-$ Cu environments depicted in the structural model, the $\mathrm{Cr}$ ligand environment is distinct in each case. At the top-left of the model, isolated $\mathrm{Cr}$ and $\mathrm{Cu}$ octahedrons are expected to exhibit the average sum of the optical and ESR properties of the reference samples, which we have excluded this case in Fig. 1(b). In contrast, the proximity of $\mathrm{Cr}$ and $\mathrm{Cu}$ octahedrons at bottom-left and to the right, should facilitate mutual interactions, beside the shared oxygen, which effectively quenches $\mathrm{Cr}^{6+}$ oxidation state, being consistent with optical and ESR results. Additional sign of adjacent/shared $\mathrm{Cr}-\mathrm{Cu}$ interactions, is the shift of the center of gravity of $\mathrm{Cu}^{2+}$ absorption band (Fig. 2) towards the nearby $\mathrm{Cr}^{3+}$ peak position. While at the high preparation temperature and rapid quenching required for glass formation many such structural models are possible, the occurrence of adjacent and shared $\mathrm{Cr}$-Cu octahedrons appeared to be preferential.

\section{Conclusion}

Binary-TM doped borate glasses of composition $x \mathrm{CuO}-(75-x) \mathrm{B}_{2} \mathrm{O}_{3}-24.7 \mathrm{Li}_{2} \mathrm{O}-0.3 \mathrm{Cr}_{2} \mathrm{O}_{3}$, were prepared using the melt-quenching techniques. Distinct optical transitions from $\mathrm{Cr}^{3+}, \mathrm{Cr}^{6+}$, and $\mathrm{Cu}^{2+}$ ions were identified. The intensity of these $\mathrm{Cr}$ transitions was found to exhibit strong intensity modulation, although the $\mathrm{Cr}$ concentration is fixed. Specifically, the $\mathrm{Cr}^{6+}$ peaks are strongly suppressed, while those of $\mathrm{Cr}^{3+}$ are barely attenuated after $\mathrm{Cu}$ doping. These optical modifications are supported by probing the oxidation states of $\mathrm{Cr}$ and $\mathrm{Cu}$ ions using electron spin resonance spectroscopy. The crystal field (10Dq), Racah parameters $(B, C)$, and the optical band gap were determined, where the latter decreases by $\sim 0.32 \mathrm{eV}$ at the highest $\mathrm{Cu}$ content. These findings are complemented by utilizing FTIR spectroscopy to map the structural modifications introduced by $\mathrm{Cu}$ additives, and a structural model assuming homogenous and preferential proximity of $\mathrm{Cu}$ and $\mathrm{Cr}$ ions within the network was proposed.

\section{Declarations}

o Ethics approval and consent to participate: Not applicable

o Consent for publication: Not applicable

o Availability of data and materials: Not applicable

\section{Funding' and/or 'Conflicts of interests'/'Competing interests}

o Competing interests: The authors have no relevant financial or non-financial interests to disclose.

o Funding: The authors did not receive support from any organization for the submitted work. 
o Authors' contributions: All listed authors contributed to the study conception and design and they all read and approved the final manuscript.

o Acknowledgements: Not applicable

Compliance and Ethical Standards:

o Disclosure of potential conflicts of interest: Not applicable

o Research involving Human Participants and/or Animals: Not applicable

o Informed consent: Not applicable

\section{References}

1. Ebrahimi, E., Rezvani, M.: Spectrochim. Acta A Mol. Biomol. Spectrosc. 190, 534 (2018)

2. Hassan, M.A., Farouk, M., Abdullah, A.H., Kashef, I., ElOkr, M.M.: J. Alloys Compd. 539, 233 (2012)

3. Samir, A., Hassan, M.A., Abokhadra, A., Soliman, L.I., Elokr, M.: Opt. Quantum Electron. 51, 123 (2019)

4. Hongli Wen, Peter, A., Tanner: J. Alloys Compd. 625, 328 (2015)

5. Hassan, M.A.: Al Azhar Bull. Sci. 9, 145 (2017)

6. Woldemar, A., Weyl: Coloured Glasses, 7th edn. Society of Glass Technology, Sheffield (2016)

7. Lakshmana Rao, B., Ravi.Babu, Y.N.Ch., Prasad, S.V.G.V.A.: J. Non Cryst. Solids 382, 99 (2013)

8. Othman, A.M., Abd El-Fattah, Z.M., Farouk, M., Moneep, A.M., Hassan, M.A.: J. Non-Cryst. Solids 558, 120665 (2021)

9. Morshidy, H.Y., Abd El-Fattah, Z.M., Abul-Magd, A.A., Hassan, M.A., Mohamed, A.R.: Opt. Mater. 113, 110881 (2021)

10. Hassan, M.A., Ahmad, F., Abd El-Fattah, Z.M.: J. Alloys Compd. 750, 320 (2018)

11. Venkateswara Rao, G., Veeraiah, N.: J. Alloys Compd. 339, 54 (2002)

12. Hassan, M.A.: J. Alloys Compd. 574, 391 (2013)

13. Aktas, B., Yalcin, S., Dogru, K., Uzunoglu, Z., Yilmaz, D.: Radiat. Phys. Chem. 156, 144 (2019)

14. Hassan, M.A., Ebrahim, F.M., Moustafa, M.G., Abd El-Fattah, Z.M., El-Okr, M.M.: J. Non-Cryst. Solids 515,157 (2019)

15. Srinivasa Rao, L., Srinivasa Reddy, M., Krishna Rao, D.: N.Veeraiah, Solid State Sci. 11, 578 (2009) 2

16. Hassan, M.A., Hogarth, C.A.: J. Mater. Sci. 23, 2500 (1988)

17. Ahmed Abokhadra, A., Samir, M.A., Hassan, L.I., Soliman, M.M., ElOkr: Egypt. J. Solids 40, 11 (2017)

18. Lever, A.B.P.: Inorganic Electronic Spectroscopy, 2nd edn. Elsevier, Amsterdam (1984)

19. Ballhausen, C.A.: Introduction to Ligand Field Theory, 2nd edn. McGraw-Hill, New York (1962)

20. Byeong-Soo Bae, M.C..Weinberg: J. Non-Cryst. Solids 168, 223 (1994) 
21. Hongli Wen, Peter, A., Tanner, B.-M., Cheng: Mater. Res. Bull. 83, 400 (2016)

22. Ahmad, F.: J. Alloys Compd. 586, 605 (2014)

23. Ravikumar, R.V.S.S.N., Komatsua, R., Ikeda, K., Chandrasekhar, A.V., Reddy, B.J., Reddy, Y.P., Rao, P.S.: J. Phys. Chem. Solids 64, 261 (2003)

24. Terczynska-Madej, A., Cholewa-Kowalska, K., Laczka, M.: Opt. Mater. 32, 1456 (2010)

25. Naga Raju, G., Veeraiah, N., Nagarjuna, G., Satyanarayana, P.V.V.: Phys. B 373, 297 (2006)

26. Ravikumar, R.V.S.S.N., Yamauchi, J., Chandrasekhar, A.V., Reddy, Y.P., Sambasiva Rao, P.: J. Mol. Struct. 740, 169 (2005)

27. Padlyak, B.V., Ryba-Romanowski, W., Lisiecki, R., Adamiv, V.T., Burak, Y.V., Teslyuk, I.M.: Opt. Mater. 34, $2112(2012)$

28. Singh, V., Sivaramaiah, G., Rao, J.L., Kim, S.H.: Mater. Res. Bull. 60, 397 (2014)

29. Little Flower, G., Srinivasa Reddy, M., Sahaya Baskaran, G., Veeraiah, N.: Opt. Mater. 30, 357 (2007)

30. Cz Koepke, K., Wi_sniewski, M., Grinberg: J. Alloys Compd. 341, 19 (2002)

31. Cz. Koepke, K., Wisniewski, M., Grinberg, A., Majchrowski, T.P.J., Han: J. Phys.: Condens. Matter. 13, 2701 (2001)

32. Cz Koepke, K., Wi_sniewski, M., Grinberg, F., Rozpłoch: J. Phys. Condens. Matter 14, 11553 (2002)

33. Durga, D.K., Veeraiah, N.: Phys. B 324, 127 (2002)

34. Kesavulu, C.R., Chakradhar, R.P.S., Jayasankar, C.K., Lakshmana Rao, J.: J. Mol. Struct. 975, 1-3 (2010) 93.

35. Ismail, A.I., Samir, A., Ahmad, F., Soliman, L.I., Abdelghany, A.: Opt. Quantum Electron. 53, 168 (2021)

36. Pisarski, W.A., Pisarska, J., Dominiak-Dzik, G., Ryba-Romanowski, W.: J. Alloys Compd. 484, 45 (2009)

37. Ismail, A.I., Samir, A., Ahmad, F., Soliman, L.I., Abdelghany, A.: J. Non-Cryst. Solids, xxx (2021) 120743

38. Ahmad, F., Nabhan, E.: Opt. Quantum Electron. 51, 261 (2019)

39. De Vicente, F.S., Santos, F.A., Simões, B.S., Dias d, S.T., Li, M.Siu: Opt. Mater. 38, 119 (2014)

40. Georges Calas, O., Majerus, L., Galoisy, L., Cormier: Chem. Geol. 229, 218 (2006)

41. Varshneya, A.K.: Fundamentals of Inorganic Glasses. Academic press Inc, New York (1994)

42. Funabiki, F., Matsuishi, S., Hosono, H.: J. Phys. Chem. A 115, 5081-5088 (2011)

43. Yao, Z.Y., Möncke, D., Kamitsos, E.I., Houizot, P., Célarié, F., Rouxel, T., Wondraczek, L.: J. Non-Cryst. Solids 435, 55 (2016)

44. Andronenko, S.I., Andronenko, R.R., Vasil'ev, A.V., O.A. Zagrebel'nyi, Glass Phys. Chem. 30: (2004) 230 45. Ibrahim, A.M., Hammad, A.H., Abdelghany, A.M., Rabie, G.O.: J. Non-Cryst. Solids 495, 67 (2018)

46. Armenak, A., Osipov, L.M., Osipova, Branislav Hruška, A.A., Osipov: Marek Liška, Vib. Spec. 103, 102921 (2019)

47. Mahesh, M., Hivrekar, D.B., Sable, M.B., Solunke, K.M., Jadhav: J. Non-Cryst. Solids 474, 58 (2017) 
48. Hverhoef, A., Den-Hartog, H.W.: J. Non-Cryst. Solids 182, 221 (1995)

49. Kamitsos, E.I., Patsis, A.P., Chryssikos, G.D.: J. Non-Cryst. Solids 152, 246 (1993)

50. Avogadro: an open-source molecular builder and visualization tool. Version 1.2. http://avogadro.cc/

51. Marcus, D., Hanwell, D.E., Curtis, D.C., Lonie, T., Vandermeersch, E., Zurek, Geoffrey, R.: Hutchison; "Avogadro: An advanced semantic chemical editor, visualization, and analysis platform". J. Cheminform. 4, 17 (2012)

\section{Figures}
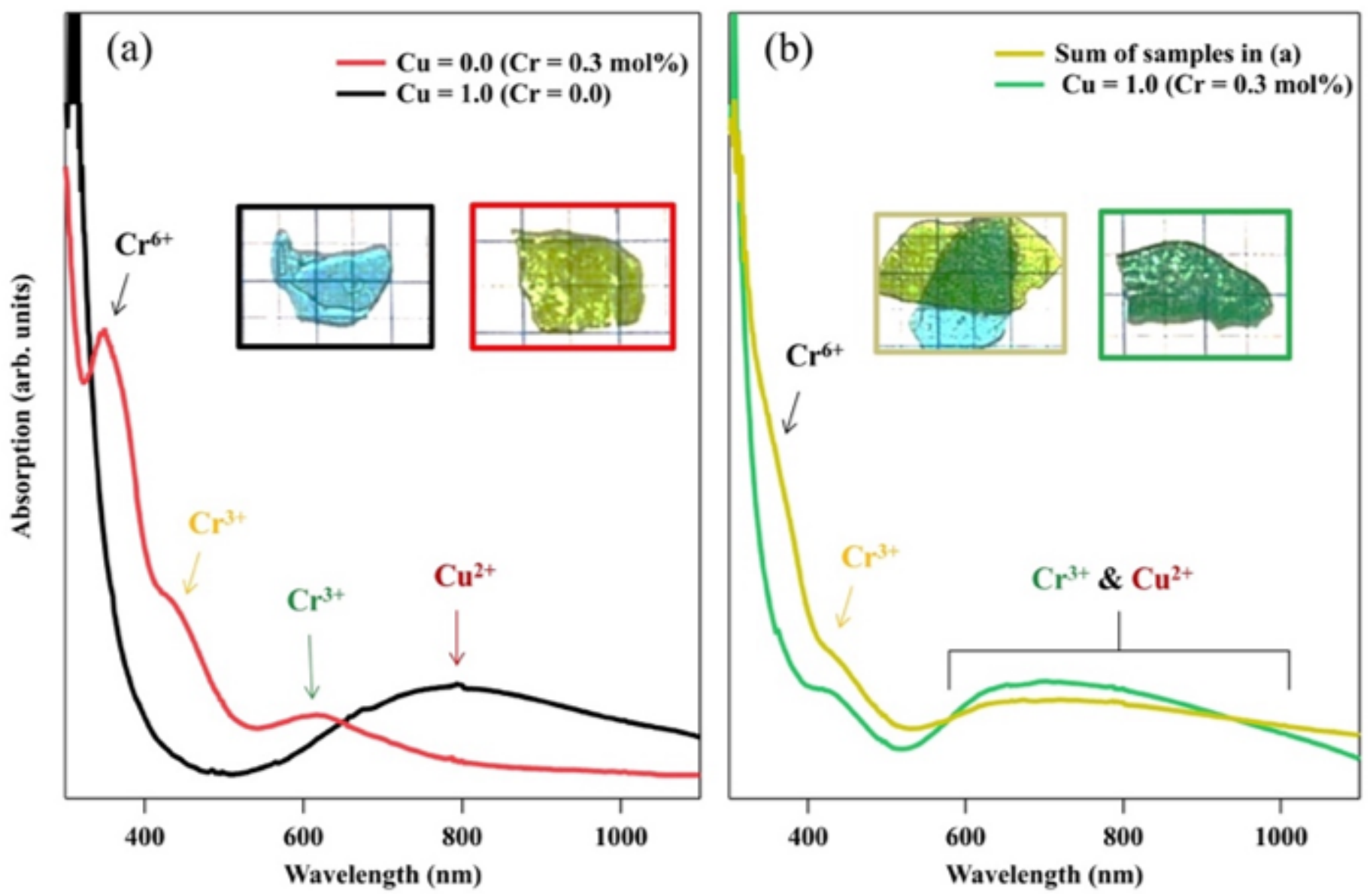

Figure 1

(a) Optical absorption spectra for reference glass samples, namely Cu-free (red) and Cr-free (black) samples. (b) The sum of the optical spectra (yellow) presented in (a) compared to the measured spectrum (green) for binary TM sample $(\mathrm{Cu}=1.0$ and $\mathrm{Cr}=0.3 \mathrm{~mol} \%)$. The insets contain photographs for the two reference samples (a), their superposition (b, left), and for the binary TM sample (right). 


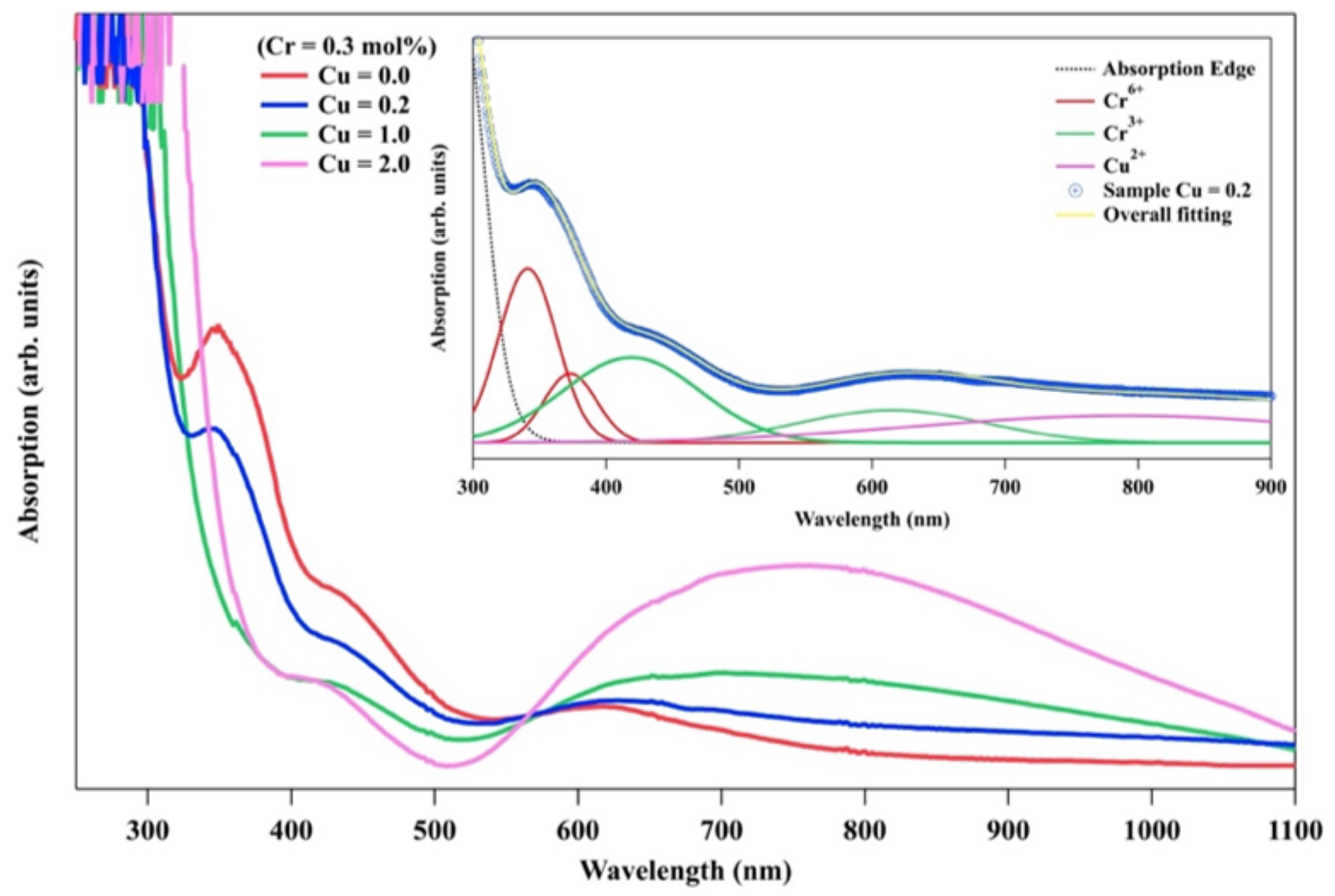

Figure 2

Optical absorption spectra for all Cu-doped samples with composition xCuO-(75-x) B203-24.7Li2O$0.3 \mathrm{Cr} 203$. The inset shows the deconvolution process for the $\mathrm{x}=0.2$ sample. The spectrum is fitted with two sharp Gaussian peaks for Cr6+(red), two relatively broad peaks from $\mathrm{Cr} 3+($ green), one boarder peak for Cu2+(pink), and an absorption edge (dotted black), where the overall fitting (yellow) nicely coincide with the experimental data points (blue). 

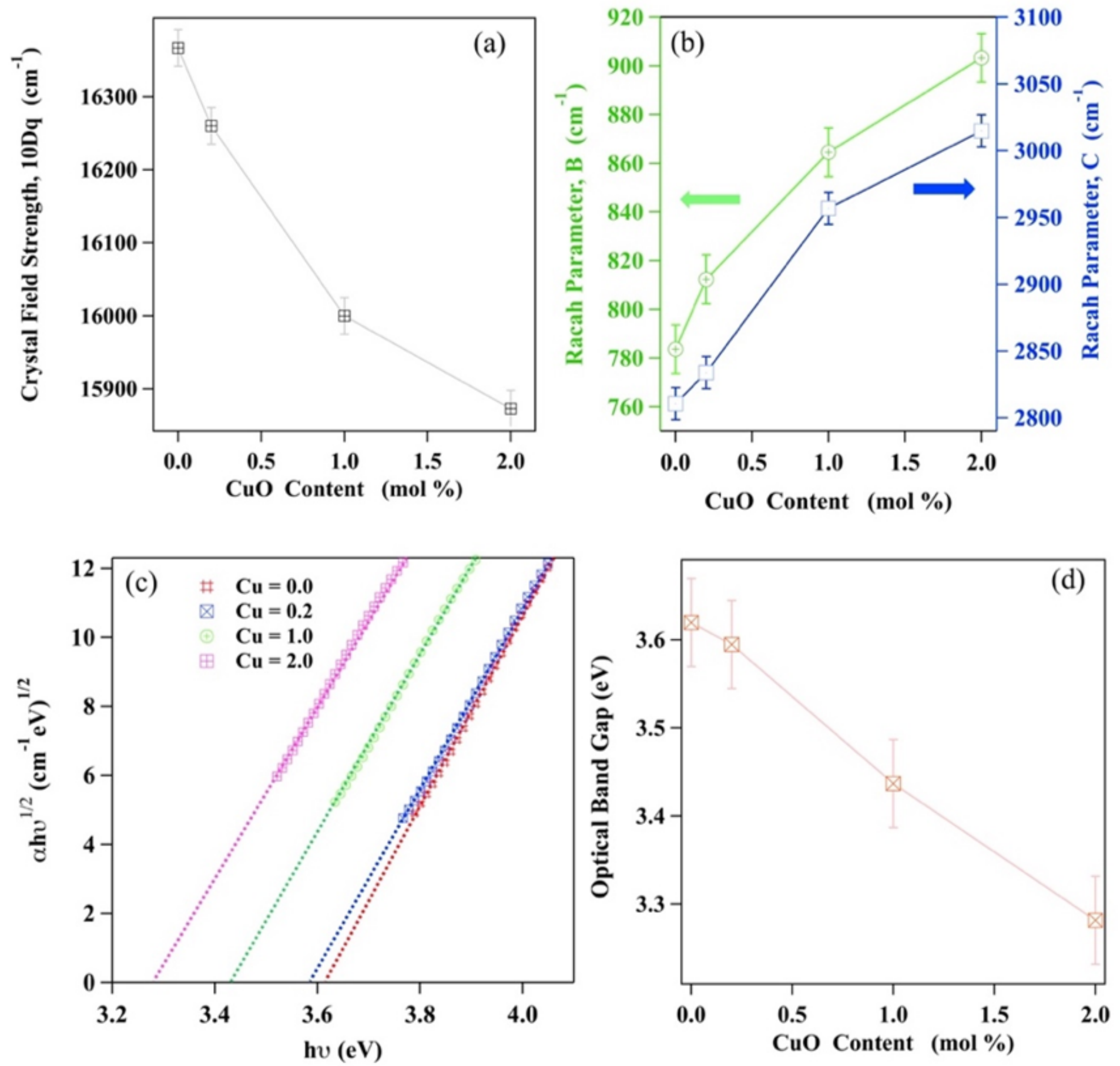

Figure 3

The estimated values for 10Dq (a) and Racah parameters (b) for all compositions xCuO-(75-x) B2O324.7Li2O-0.3Cr203. (c-d) Tauc's plots (c) and the estimated optical band gap (d) for the investigated samples. 


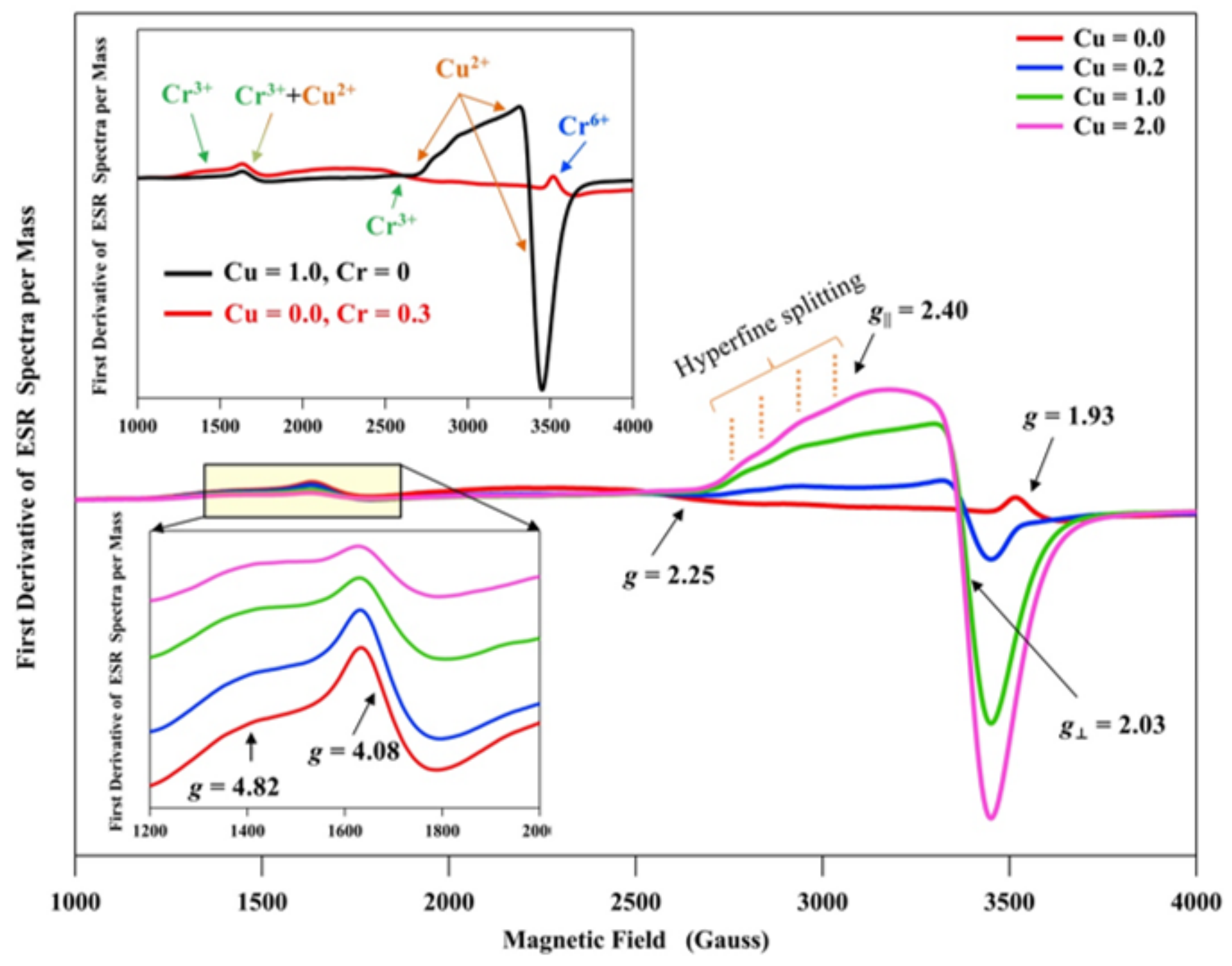

Figure 4

ESR spectra for all Cu-doped samples with composition xCuO-(75-x) B203-24.7Li20-0.3Cr203. The upper inset contains the spectra of the two references, namely $\mathrm{Cr}$ - and $\mathrm{Cu}$-free samples, while lower inset shows a close-up view for the low field $\mathrm{Cr} 3+$ signal. Hyperfine splitting form Cu2+ at $\mathrm{g} \| \approx 2.4$ is indicated by dashed lines. 


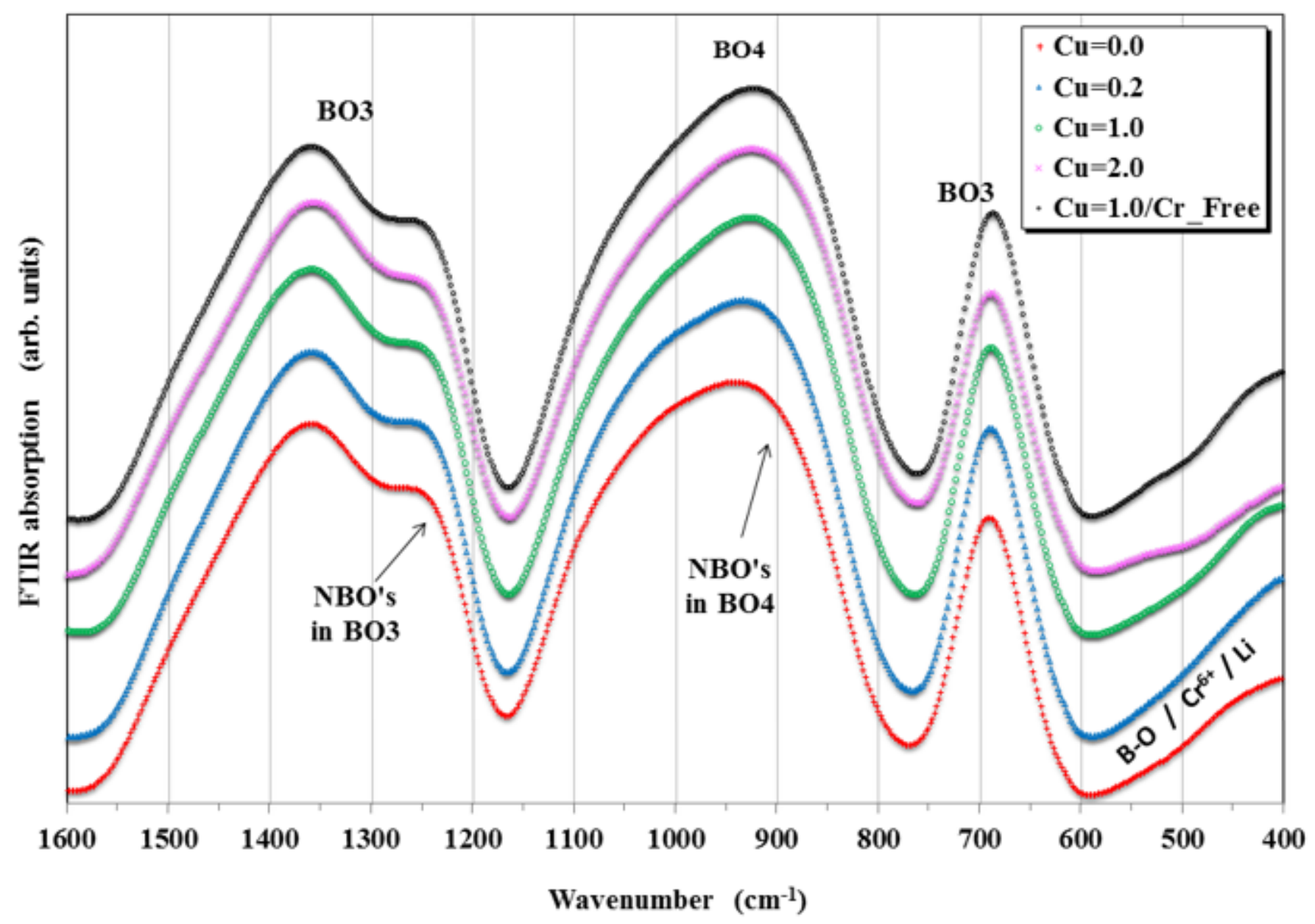

Figure 5

FTIR spectra for all Cu-doped samples with composition xCuO-(75-x) B2O3-24.7Li20-0.3Cr203. The borate structure units, $\mathrm{BO} 3$ and $\mathrm{BO} 4$, as well as their respective $\mathrm{NBO}$ are marked. 


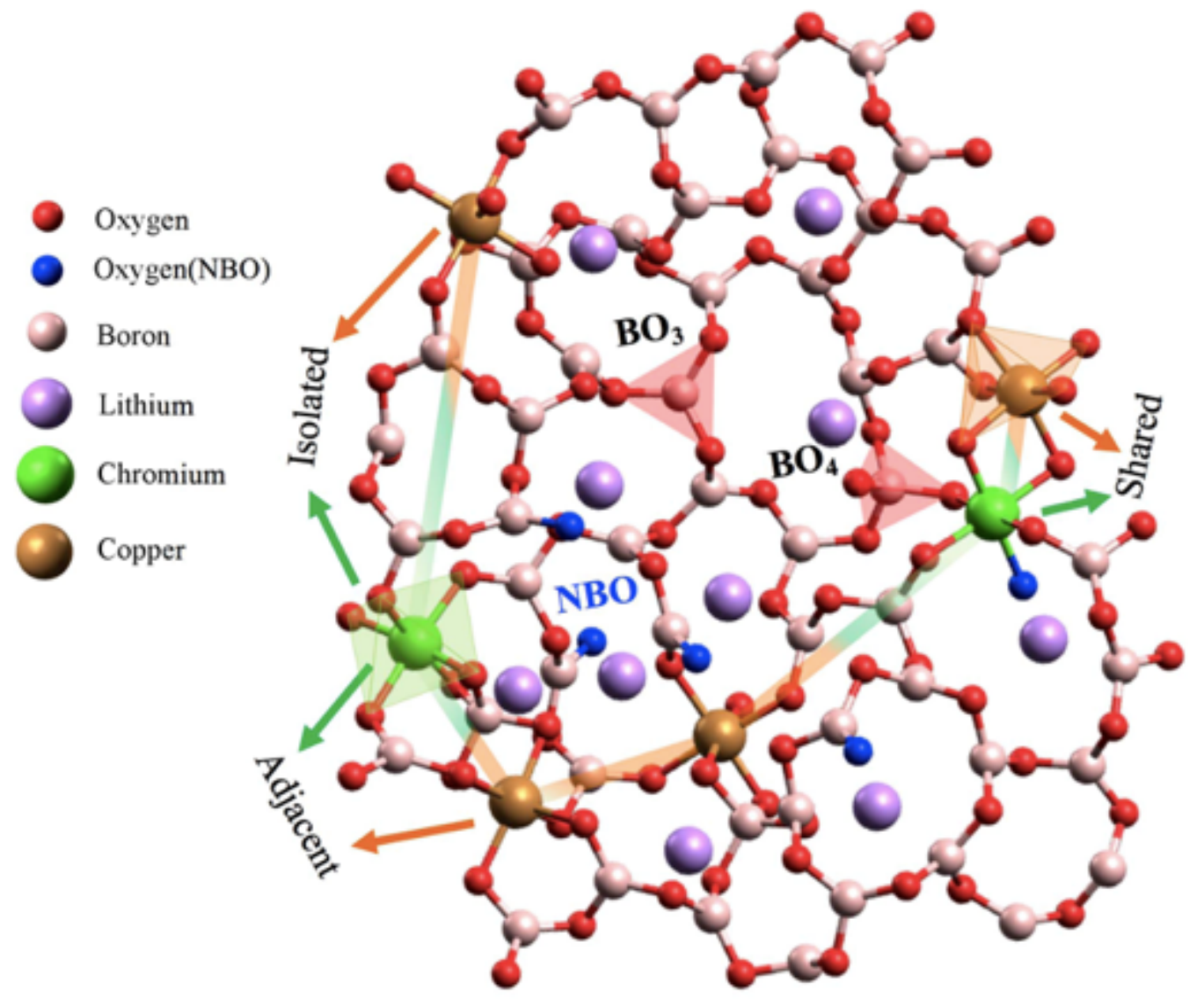

Figure 6

Structural models for an alkali-borate glass network containing isolated, adjacent, and shared $\mathrm{Cr}$ and $\mathrm{Cu}$ ions in octahedral coordination. Selected $\mathrm{BO} 3$ and $\mathrm{BO} 4$ structural units as well as $\mathrm{Cr}$ and $\mathrm{Cu}$ octahedrons are marked. The faint green-brown lines highlight the separation between TM ions.

\section{Supplementary Files}

This is a list of supplementary files associated with this preprint. Click to download.

- GraphicalAbstract.png 